\title{
Türk Futbolunda Video Yardımcı Hakem (VAR) Uygulamasına Yönelik Tutum Ölçeği Geliştirilmesi
}

DOI: $10.26466 /$ opus.673635

*

\author{
$\underline{\text { Recep Fatih Kayhan }}^{*}$ - Sait Bardakçı** - Çağdaş Caz *** \\ * Arş. Gör. Dr., Recep Tayyip Erdoğan Üniversitesi, Beden Eğitimi ve Spor Y.O, Rize/Türkiye \\ E-Posta: fatihkayhan8@hotmail.com \\ ORCID: 0000-0002-1022-2892 \\ ** Dr. Öğretim Üyesi, Sivas Cumhuriyet Üniversitesi, İ̈BF/İşletme Bölümü, Sivas/Türkiye \\ E-Posta: Sait_bardakci@hotmail.com \\ ORCID: 0000-0003-3720-5029 \\ *** Doç. Dr., Yozgat Bozok Üniversitesi, Spor Bilimleri Fakültesi, Yozgat/Türkiye \\ E-Posta: cazcagdas@gmail.com \\ ORCID: 0000-0003-0262-6114
}

Öz

Geçmişten günümüze gelinceye dek hem seyirci/taraftar kitlesini hem de seyir zevkini arttırmaya devam ettiren futbol, günümüzde en çok izlenen ve takip edilen spor dallarından biri olmuştur. Futbol maçı esnasinda hakemlerin vermiş olduğu kararlar maç sonucuna doğrudan etki etmektedir. Hakemlerin vermiş olduğu kararlar çoğu zaman tartısmaya sebebiyet vermektedir. Hatal kararlarm önüne geçebilmek gelişen teknoloji ile mümkün olabilmektedir. Bu amaçla geliştirilen Video Yardımo Hakem (VAR), son karar noktasında hakemlere büyük kolaylık sağlamaktadır. Fakat bununla birlikte VAR uygulaması hakkında futbol kamuoyundaki tartışmalar tazeliğini korumaktadır. Futbolun çeşitli paydaşlar uygulama hakkında olumlu veya olumsuz görüşlerini futbol kamuoyuyla paylaşmaktadır. Bu düşüncelerden hareketle çalışmanın amacı Türk futbolunda VAR uygulamasına yönelik bireylerin tutumlarım ölçmeye yarayan bir ölçek geliştirmektir. Bu amaçla araştırmacllar tarafindan 43 maddelik bir madde havuzu oluşturulmuş, uzman görüşleri doğrultusunda 5 madde kapsam dışı bırakılarak 38 maddelik taslak ölçek elde edilmiştir. İstatistiksel yöntem olarak açımlayıcı ve doğrulayıcı faktör analizleri, test tekrar test yöntemi ve iç tutarllık analizi kullanılmıştır. Taslak ölçeğe uygulanan açımlayıcı faktör analizi sonucunda 4 alt boyuttan ve 20 maddeden oluşan bir ölçme yapısı elde edilmiş, doğrulayıcı faktör analizi ile bu yapının geçerliliği teyit edilmiştir. Ölçĕğin güvenirliği test tekrar test yöntemi ile ve iç tutarlılı analizi ile incelenmiştir. Yapılan analizler sonucunda ölçeğin kararllık katsayısı 0,994 olarak, Cronbach Alpha iç tutarllık katsayısı 0,893 olarak, Spearman-Brown yarı güvenirlik katsayısı ise 0,911 olarak hesaplanmıştır. Bu bulgulara göre geliştirilmiş olan ölçeğin güvenilir ve geçerli bir ölçme aracı olduğu sonucuna varılmıştır.

Anahtar Kelimeler: Video Yardımcı Hakem, Tutum Ölçeği, Güvenirlik, Geçerlik 


\title{
Development of The Attitude Scale Towards Video Assistant Referee (Var) in Turkish Football
}

\begin{abstract}
From past to present, football has continued to increase both the audience fans and the viewing pleasure and has become one of the most watched and followed sports. The decisions of the referees during the football match have a direct effect on the result of the match. The decisions of the referees are often controversial. It is possible to prevent wrong decisions with the developing technology. The Video Assistant Referee (VAR), which was developed hereby, provides great convenience to the refrees at the final decision. However, discussions about the application of VAR remain fresh at football public opinion. The various stakeholders of football share their positive or negative opinions about the application of $V A R$ with the public. The aim of this study is to develop a scale that measures the attitudes of individuals towards the application of VAR in Turkish football. For this purpose, a pool of 43 items was created by the researchers and 5 items were excluded from the scope of expert opinions and a 38-item draft scale was obtained. Exploratory and confirmatory factor analyzes, test-retest method and internal consistency analysis were used as statistical methods. As a result of the exploratory factor analysis applied to the draft scale, a measurement structure consisting of 4 sub-dimensions and 20 items was obtained and the validity of this structure was confirmed by confirmatory factor analysis. The reliability of the scale was examined by test-retest method and internal consistency analysis. As a result of the analysis, the stability coefficient of the scale was calculated as 0.994, the internal consistency coefficient of Cronbach Alpha was 0.893, and the Spearman-Brown half reliability coefficient was calculated as 0.911. It was concluded that the scale developed according to these findings is a reliable and valid measurement tool..
\end{abstract}

Keywords: Video Assistant Refree, Attitude Scale, Reliability, Validity 


\section{Giriş}

Futbol maçlarında gol pozisyonları ve fauller ile ilgili tartışmaların önüne geçebilmek ancak gelişen teknoloji imkânlarının futbol kuralları ile birleştirilerek, hakemlerin daha doğru ve adil kararlar vermesinin sağlanması ile mümkün olmaktadır (Peker ve Özkaraca, 2018). Dijital medya teknolojilerinin futbola girmesiyle birlikte maç esnasında oluşan kritik ve zorlu pozisyonlara ilişkin karar verme durumu daha net ve rahat bir duruma dönüşmüştür (Ugondo ve Tsokwa, 2019).

İlk olarak 2016 yılı Eylül ayında İtalya ile Fransa arasında oynanan hazırlık maçında denenen ve sadece gol pozisyonu için değil, maçtaki kritik pozisyonlar için de önerilen Video Yardımcı Hakem (Video Assistant Refree-VAR) Sistemi, maç esnasında oluşan kritik kararlar için hakemlerin karar vermesine yardımcı olmaktadır. Hakem kameralar ile elde edilen verilerden bilgisayarlı görü teknikleri ile kendisine yardımcı araçlar oluşturarak geriye yönelik pozisyonları maçı durdurarak değerlendirdikten sonra nihai kararını vermiştir. Bu bağlamda yardımc teknolojik yenilikler olarak da ifade edilen VAR, yüksek çözünürlüğe ve kaliteye sahip kameralar ile alınan görüntülerin gerçek zamanlı işlenerek hakemlerin doğru karar verebilmesini sağlayan bilgisayarlı sistem olarak adlandırılmaktadır (Peker ve Özkaraca, 2018).

Futbol hakemlerinin maç esnasında göremeyerek kaçırdıkları pozisyonları önlemek amacıyla geliştirilen VAR sistemi, maç esnasında meydana gelen pozisyonları tekrar izlemeye olanak sunmaktadır (Gore, Rix, Wathelet ve Cazemajou, 2012). Ayrıca, saha içerisinde gelişen olumsuz durumların tekrardan izlenmesine de imkân tanımaktadır (Ford, ve ark., 1999). VAR sadece hakem (ilk/asıl) bir karar verdikten sonra veya ciddi bir olayın kaçırılması ve bu durumun maç yetkilileri tarafından görülmemesi durumunda kullanılır. Hakemin asıl kararı, "net ve açık bir hata" olmadıkça değiştirilmemektedir (Paolo-spagnolo ve ark., 2013).

Yapılan alan yazın taraması sonucunda yerli ve yabanc literatürde mevcut konu (VAR) ile ilgili sınırlı sayıda çalışmanın (Dandıl ve Özkul, 2019; Orta, 2018) yer aldığı görülmektedir. Bunun nedeni ise VAR sisteminin dünyada ilk olarak 2016 yılında, Türkiye'de ise ilk olarak 2018-2019 Spor Toto Süper Lig Lefter Küçükandonyadis Sezonu'nda uygulanmaya başlamış olmasıdır. Bu nedenle mevcut çalışmanın yapılacak araştırmalara kaynak oluşturması bakımından önemli olduğu söylenebilir. 
Literatürde, spor yorum programlarında, gazete ve dergilerde VAR sistemi hakkında olumlu ve olumsuz birçok görüşün yer aldığı görülmektedir. VAR uygulamasının oyunu değil skoru koruma odaklı olduğu belirtilerek, bu sistemin varoluşsal bir sorun olduğu savunulmuştur. Bunun yanı sıra Hırvat futbolcu Luka Modric ise, bu yeni buluşun kafa karışıklığına neden olduğunu, uygulamadan vazgeçilmesi gerektiğini savunarak VAR uygulaması hakkındaki düşüncelerini aktarmıştır (Dizdar, 2019). Yapılan bir diğer araştırmada ise, pek çok ülkede uygulanmasına rağmen VAR sistemine tarafların ön yargılı bir tutum içerisinde oldukları tespit edilmiştir (Engin ve Çelik, 2019).

Türkiye Futbol Federasyonu (TFF) Başkanı Nihat Özdemir, Antalya'da düzenlenen 2019-2020 Sezonu Merkez Hakem Kurulu (MHK) Kış Semineri'nin resmi açılışı töreninde VAR uygulaması hakkında şu ifadeleri kullanmıştır (TFF, 2020): “Video Yardımcı Hakem (VAR) uygulaması futbolda tartışmayı yüzde 100 oranında bitirmek için değil, yüzde 100 skandal kararları engellemek için getirilmiştir. Eskisi gibi yarım metre, 1 metre ofsayttan atılan golleri, ceza sahası dışında verilen penaltıları, elle atılan bariz golleri görmüyoruz. Peki VAR'ın eleştirebileceğimiz noktaları yok mu? Var... O da inceleme sürelerinin uzaması, oyunun soğuması gibi tenkitler. Bu bütün dünyanın sorunu ve bütün önde gelen liglerde tartışllıyor. Sistem inaniyorum ki zamanla daha da gelişecektir". Aynı seminerde 2018 FIFA Dünya Kupası'ndan sonra herkesin VAR sistemine olan isteğinin ve inancının arttı̆ı̆ı dile getiren Külüpler Birliği Başkan Yardımcısı ve Demir Grup Sivasspor Kulübü Başkanı Mecnun Otyakmaz ise konuyla alakalı olarak şu görüşleri paylaşmıştır (TFF, 2020): "Fakat ülkemizdeki uygulamaları görünce ne yazık ki hayal kırıklıkları yaşadığımız da bir gerçek. VAR konuşmaları, VAR çizgileri ve VAR'a gidip-gitmemek kamuoyunda yeni gündemler oluşturdu. VAR sistemini destekliyoruz ve ikinci yarıda daha iyi iletişimle problemleri azaltmanızı bekliyoruz. VAR kayıtlarının, toplumu bilinçlendirmek adına örnek teşkil edebilecek bazı kritik pozisyonlarda kamuoyu ile paylaşılması fikrini destekliyorum"

Türk futbol kamuoyundaki bu görüşler VAR uygulamasının üzerindeki tartışmaların sistem tam oturuncaya kadar süreceğini göstermektedir. Mevcut araştırma futbolun bu farklı düşünce taraflarının ve paydaşlarının VAR sistemi tutumlarının tespit edilmesine, değerlendirilmesine ve karşılaştırılmasına olanak sağlaması açısından önem arz etmektedir. 
Tutum, kişinin kendine ya da etrafındaki herhangi bir obje, toplumsal mevzu veya hadiseye karşı tecrübe, motivasyon ve bilgilerine dayanarak örgütlediği zihinsel, duygusal ve hareketsel bir reaksiyon, ön eğilimidir (İnceoğlu, 2010). Tutumlar, sosyal psikoloji konusunda güncelliğini koruyan bir kavramdır. Bu güncelliğin sebebi tutumların ortaya çıkacak olan davranışı etkilediği varsayımıdır. Davranışların önceden kestirilebilmesine imkan tanıdığından dolayı tutumların bilinmesi de önem kazanmaktadır (Arkonaç, 2001).

Tutumların ölçümleri ile ilgili çalışmalar genel olarak üç genel kategori altında toplanabilir (Anderson, 1988; Arul, 2002; Akt: Kartal ve Bardakçı, 2019). Bunlar sirasiyla;

- Bireylerin ortaya koydukları davranışlardan çıkarsamalar yapmaya imkân sağlayan yöntemlerdir.

- Bireylerin fizyolojik tepkilerine dayalı olarak çıkarsama yapmaya olanak tanıyan yöntemlerdir.

- Bireylerin bir dizi ifade veya maddeye verdikleri tepkilere dayanarak çıkarsama yapmaya imkân sağlayan yöntemlerdir. Bu yöntemler ölçek olarak adlandırılan ölçme araçlarından meydana gelmektedirler.

Literatür incelendiğinde, spor paydaşlarının VAR sistemi ile ilgili tutumların bilimsel olarak ortaya koyacak bir ölçme aracına rastlanmamıştır. $\mathrm{Bu}$ bağlamda bu araştırmanın amacı, yukarıda bahsedilen tutum ölçme yaklaşımlarından üçüncüsü esas alınarak Türk futbolunda VAR uygulamasına yönelik tutumların belirlenmesine imkân sağlayacak bir ölçek geliştirmektir.

\section{Yöntem}

Araştırmada metodoloji olarak bir ölçek geliştirme çalışması için temel olarak gerekli olan aşağıdaki adımlar izlenmiştir (Kartal ve Bardakçı, 2018; Tavşanc1l, 2002):

- Madde havuzunun oluşturulması,

- Madde havuzunun kapsam geçerliğinin incelemesi amaciyla uzman görüşüne sunulması,

- Madde havuzundaki ifadelerin anlaşılırlığını ve dil kurallarına uygunluğunu değerlendirmek için taslak ölçeğin dil uzmanlarına sunulması,

- Taslak ölçeğin çalışma grubuna uygulanması, 
- Ölçeğin yapı geçerliğinin değerlendirilmesi için Açımlayıcı Faktör Analizi (AFA) ve Doğrulayıc Faktör Analizinin (DFA) yapılması,

- Madde analizinin yapilması,

- Ölçeğin güvenirliğinin test tekrar test uygulaması bağlamında değerlendirilmesi,

- Ölçeğin güvenirliğine ilişkin Cronbach Alfa iç tutarlılık katsayısının ve Spearman-Brown yarılama güvenirlik katsayısının hesaplanması.

\section{Çalışma Grubu}

Araştırmanın çalışma grubunu Türkiye'deki futbol müsabakalarını takip eden, futbol hakkında yeterince bilgi sahibi olan 1011 kişi oluşturmaktadır. Çalışma grubunun belirlenmesinde kolayda örnekleme yöntemi kullanılmıştır. Çalışma grubundaki kişilerden gönüllü katılım ilkesi doğrultusunda yüz yüze anket yolu ile veri toplanmıştır. Kişilere futbol maçlarını takip edip etmedikleri ve futbol oyun kuralları hakkında yeterince bilgi sahibi olup olmadıkları sorulmuş, yeterli bilgi sahibi olduğunu belirten kişilere ölçek formu uygulanmıştır. Yapı geçerliğinin incelenmesi aşamasında gerekli olan açımlayıcı faktör analizi için 415, doğrulayıcı faktör analizi içinse 304 kişiye ait veriler kullanılmıştır ve bu iki örneklem birbirinden bağımsızdır. Ölçeğin güvenirlik analizlerinde ise test tekrar test uygulamasında 42 kişiye, madde analizi ve Cronbach Alpha katsayısının hesaplanması aşamalarında 250 kişiye ait veriler değerlendirmeye tabi tutulmuştur.

\section{Ölçeğin Yapısı}

Geliştirilen ölçek 7'li Likert tipinde bir ölçektir. Ölçekte yer alan maddeler, "7= Tamamen Katilıyorum", "6= Katilıyorum", “5= Kismen Kat1lyorum”, " $4=$ Kararsizım”, " $3=$ Pek Katılmiyorum”, “2= Katılmıyorum” ve " $1=$ Kesinlikle Katılmıyorum" şeklinde puanlanmaktadır. Ölçekten alınan puanlar yediye yaklaştıkça kişilerin o maddedeki önermeye katılım düzeylerinin yüksek, bire yaklaştıkça ise düşük olduğunu göstermektedir. Konuyla ilgili olumsuz tutumu yansitan ifadeye sahip maddeler puanlama aşamasında yukarıdaki kodlamanın tam tersine olarak puanlanmaktadır. 


\section{Madde Havuzunun Oluşturulması}

Ölçeğin madde havuzunda yer alacak olan maddeler araştırmacılar tarafından oluşturulmuştur. Geliştirilecek olan ölçeğin konusuyla ilgili ilk ölçek olmasından dolayı ölçeğe madde tedarikinde literatürden faydalanmak mümkün olmamıştır. Bu nedenle Türk futbol kamuoyunda VAR uygulamasıyla ilgili dile getirilen olumlu ve olumsuz görüşler dikkate alınmıştır. Ayrıca, futbol hakemliği, futbol antrenörlüğü yapmış, futbol araştırmalarında bulunan uzmanlar ile tutum alanında çalışmaları bulunan uzmanların görüşü alınarak 24 tane olumlu, 19 tane olumsuz ifade düzenlenmiştir. Bu şekilde ölçeğin madde havuzu toplam 43 maddeden meydana gelmiştir.

\section{Kapsam Geçerliği İçin Uzman Görüşüne Başvurulması}

Bir ölçeğin kapsam geçerliğinin olması için, ölçme aracının içerdiği maddelerin tümünün, ölçülen özelliği ölçer nitelikte olması ve ölçülen özelliğin her bir ayrıntısının ölçekteki maddelerce sorgulanıyor olması gerekir. Diğer bir deyişle bir ölçme arac ölçmeyi amaçladığı özelliğin kavramsal altyapısını tüm yönleriyle ölçtüğü düzeyde kapsam geçerliğine sahiptir denilebilir (Kartal ve Bardakçı, 2018). Türk futbolunda VAR uygulamasına yönelik tutum ölçeğinin maddelerinin kapsam geçerliği bağlamında değerlendirilmesi için oluşturulan madde havuzu, futbol araştırmalarında bulunan ve spor psikolojisi alanında birikim sahibi 3 uzman kişiye sunularak kendilerinden görüş alınmıştır. Bu üç uzmandan alınan görüşlerin ikisi karşlıklı görüşme yoluyla, birisi ise e-posta yoluyla elde edilmiştir.

Uzmanlar madde havuzunda yer alan her bir maddeyi ölçekte yer alıp almaması gerektiği yönünde değerlendirmiş ve bu işlemin sonucunda uzmanların önerileri doğrultusunda ölçek kapsamı dışında kalan 5 madde ölçekten çıkarılmıştır. Çıkarılan maddelerden üçü olumlu, ikisi ise olumsuz tutum belirten ifadelerdir. Bu şekilde 21'i olumlu, 17'si olumsuz olmak üzere toplam 38 maddeden oluşan taslak ölçek elde edilmiştir. Taslak ölçekte yer alan madde ifadelerinin anlatım bakımından uygun olup olmadığı ve yazım kurallarına uygunluğu hakkında Türk Dili alanında uzman olan 2 akademisyenin bilgisine başvurularak ölçekte yer alan ifadeler tekrar düzenlenmiş ve taslak ölçeğe son hali verilmiştir. 


\section{Bulgular}

\section{Yapı Geçerliğine İlişkin Bulgular}

Ölçek geliştirme çalışmalarında ölçeğin ölçme yapısının ortaya konulabilmesi için en yaygin kullanılan yöntemin faktör analizi olduğu ifade edilmektedir. Faktör analizi sonucunda ölçeğin genel faktörü, buna ait alt boyutlar ve bu alt boyutların sayısı hakkında bilgi edinilir. Ortaya çıkan mevcut alt boyutlar adlandırılarak ölçek yapısı oluşturulmuş olur (Tavşancıl, 2002). Bu çalışmada da, öncelikle ölçeğin ölçme yapısının belirlenmesi amacıyla 415 katılımcıdan elde edilen veriler üzerinde açımlayıcı faktör analizi uygulanmıştır.

Bir veri setine AFA uygulanabilmesi için gerekli kriterlerden ilki örneklem büyüklügünün yeterli olup olmadığıdır. Bu bağlamda öncelikle örneklem büyüklügünün faktör analizi yeterliliğinin saptanması amaciyla Kaiser-Meyer-Olkin (KMO) istatistiği dikkate alınmıştır. Kaiser, hesaplanan KMO değerinin 0,90 'larda mükemmel, 0.80 'lerde çok iyi, 0.70 'lerde ve 0.60 'larda vasat, 0.50'nin altında ise kabul edilemez derecede olduğunu ifade etmektedir (Tavşancl, 2002). Bu aşamada 38 maddelik taslak ölçeğe ait verilere ilişkin KMO istatistiği 0.907 olarak hesaplanmıştır. Buna göre örneklem büyüklüğünün faktör analizi için mükemmel düzeyde yeterli olduğu belirlenmiştir. Veri setine AFA uygulanabilmesi için gerekli bir diğer test ise Bartlett küresellik (sphericity) testidir. Faktör analizinde değişkenler arasında yüksek korelasyon ilişkisi aranmaktadır. Ana kütle içindeki değişkenler arasında manidar ilişkilerin olup olmadığı Bartlett testi ile incelenmektedir (Nakip, 2006). Küresellik varsayımının sağlanması için analiz sonucunda Bartlett test istatistiğinin yüksek çıkması ve anlamlı olması beklenmektedir (Tavşancıl, 2002). Taslak ölçeğe yönelik yapılan analiz sonucunda değişkenler arasında yüksek ve anlamlı ilişkiler bulunduğu ve küresellik varsayımının sağlandığı tespit edilmiştir $\left(\chi^{2}=4194,545 ; \mathrm{p}<0,001\right)$.

Türk futbolunda VAR uygulamasına yönelik tutum ölçeğinin faktör yap1sını belirlenmesi amaciyla Temel Bileşenler Analizi ve Varimaks Rotasyon yöntemleri kullanılarak taslak ölçekte yer alan 38 maddeye AFA uygulanmıştır. Hiçbir faktör altına yerleşmeyen ve faktör yükü iki veya daha fazla faktörde çok yakın olan ve binişik olarak nitelendirilebilecek maddeler belirlenerek ölçekten çıkarılmıştır. Bu şekilde 18 maddenin ölçekten çıkarılmasıyla 
kalan 20 maddeye son kez AFA uygulanmış ve ilgili tablodaki sonuçlar elde edilmiştir (Tablo 1).

Tablo 1. Açımlayıcı Faktör Analizi Sonuçları

\begin{tabular}{|c|c|c|c|c|c|}
\hline Ölçek Alt Boyutu & Maddeler & Fak. Yük Değeri & Özdeğer & Varyans (\%) & $\begin{array}{l}\text { Kümülatif } \\
\text { Varyans (\%) }\end{array}$ \\
\hline \multirow{7}{*}{ Faktör 1} & Madde 15 & 0,823 & \multirow{7}{*}{7,276} & \multirow{7}{*}{36,379} & \multirow{7}{*}{36,379} \\
\hline & Madde 14 & 0,806 & & & \\
\hline & Madde 4 & 0,722 & & & \\
\hline & Madde 16 & 0,701 & & & \\
\hline & Madde 3 & 0,685 & & & \\
\hline & Madde 12 & 0,683 & & & \\
\hline & Madde 26 & 0,628 & & & \\
\hline \multirow{6}{*}{ Faktör 2} & Madde 29 & 0,766 & \multirow{6}{*}{2,544} & \multirow{6}{*}{12,722} & \multirow{6}{*}{49,102} \\
\hline & Madde 28 & 0,765 & & & \\
\hline & Madde 2 & 0,763 & & & \\
\hline & Madde 19 & 0,762 & & & \\
\hline & Madde 10 & 0,749 & & & \\
\hline & Madde 8 & 0,721 & & & \\
\hline \multirow{4}{*}{ Faktör 3} & Madde 22 & 0,803 & \multirow{4}{*}{1,891} & \multirow{4}{*}{9,453} & \multirow{4}{*}{58,554} \\
\hline & Madde 23 & 0,754 & & & \\
\hline & Madde 20 & 0,715 & & & \\
\hline & Madde 1 & 0,617 & & & \\
\hline \multirow{3}{*}{ Faktör 4} & Madde 34 & 0,821 & \multirow{3}{*}{1,134} & \multirow{3}{*}{5,671} & \multirow{3}{*}{64,225} \\
\hline & Madde 13 & 0,804 & & & \\
\hline & Madde 5 & 0,788 & & & \\
\hline
\end{tabular}

Öz değer, uygun faktör sayısını belirlemede kullanılan önemli bir katsayıdır ve uygulamada genellikle öz değeri 1 ya da 1'den büyük olan faktörler uygun faktör olarak alınmaktadır. Bu kritere Kaiser kriteri denilmektedir (Kartal ve Bardakçı, 2018). Tablo 1'de görüldüğü gibi AFA sonucunda Kaiser kriterine göre öz değeri 1'den büyük olan 4 alt boyut elde edilmiştir. Ölçekteki alt boyut sayısının belirlenmesinde ve yapı geçerliğinin sağlanmasında önemli olan bir diğer kriter ise toplam açıklanan varyanstır. Tablo 1'deki açıklanan varyans değerleri göz önüne alındığında, söz konusu 4 faktörlü yapının toplam varyansın \% 64,225'ini açıkladığı görülmektedir. Faktörlerin açıkladıkları varyans oranları ise sırasıyla Faktör 1 için \%36,379; Faktör 2 için \%12,722; Faktör 3 için \%9,453 ve Faktör 4 için \%5,671 şeklindedir.

Maddelere ait faktör yük değerleri için literatürde, genellikle 0,45 üzeri değerlerin madde seçimi için yeterli bir ölçüt olduğu belirtilmektedir (Büyüköztürk, 2002). Tablo 1'e bakıldığında belirtilen maddelere ait faktör yük de- 
ğerlerinin 0,617-0,823 aralığında değiştiği görülmektedir. Buna göre, 4 faktörlü modelde yer alan her bir maddenin faktör yük değerlerinin oldukça yüksek ve yeterli değerler olduğu söylenebilir.

AFA sonucunda ortaya konulan 4 alt boyuttan ve 20 maddeden oluşan Türk futbolunda VAR uygulamasına yönelik tutum ölçeğinin ölçme yapısının geçerliğini incelemek için ise 304 katılımcıdan oluşan bağımsız bir diğer örneklemden elde edilen verilere AMOS 23 paket programı kullanılarak DFA uygulanmıştır. DFA sonucunda kurulan ölçüm modelinin verilerle uyumlu olup olmadığı uyum indeksleri yardımıyla belirlenmektedir. Literatürde bu uyum indekslerinden $\chi^{2} / \mathrm{sd}, \mathrm{GFI}, \mathrm{CFI}, \mathrm{TLI}, \mathrm{IFI}, \mathrm{RMSEA} v \mathrm{vb}$. değerler yaygın olarak kullanılmaktadır (Karagöz, 2016). Bu indekslerin sağlaması gereken kritik değerler Tablo 2'deki gibidir (Meydan ve Şeşen, 2015).

Tablo 2. Uyum İndeksleri İçin Kritik Değerler

\begin{tabular}{lll}
\hline Uyum İndeksleri & Iyi Uyum & Kabul Edilebilir Uyum \\
\hline$\chi^{2} /$ sd & $\leq 3$ & $\leq 5$ \\
\hline GFI & $\geq 0,90$ & $\geq 0,85$ \\
\hline IFI & $\geq 0,95$ & $\geq 0,90$ \\
\hline TLI & $\geq 0,95$ & $\geq 0,90$ \\
\hline CFI & $\geq 0,97$ & $\geq 0,95$ \\
\hline RMSEA & $\leq 0,05$ & $\leq 0,08$ \\
\hline
\end{tabular}

Yapılan DFA sonucunda modele ait uyum indeksi değerleri sırasıyla $\chi^{2} / \mathrm{df}=2,200<3 ; 0,90<\mathrm{GFI}=0,920 ; 0,95<\mathrm{IFI}=0,953 ; 0,90<\mathrm{TLI}=0,944 ; 0,95<\mathrm{CFI}=0,952$ ve $R M S E A=0,054<0,08$ şeklinde hesaplanmıştır. Bu değerler Tablo 2'deki kritik değerlerle karşılaştırıldığında modelin verilere $\chi^{2} / \mathrm{sd}$, GFI ve IFI indekslerine göre iyi uyum, TLI, CFI ve RMSEA indekslerine göre ise kabul edilebilir derecede uyum gösterdiği görülmektedir. Bu bulgulara göre, AFA ile ortaya konulan 4 alt boyutlu ölçme yapısının geçerliği, bağımsız bir örneklem üzerinde doğrulanmıştır.

DFA'da regresyon katsayılarının anlamlı olması gerekliliği de bir diğer önemli noktadır. Regresyon değerleri, maddelerin faktörleri tahmin gücünü, diğer bir deyişle faktör yüklerini ifade etmektedir (Karagöz, 2016). DFA sonucunda standart faktör yük değerlerinin 0,40' in üzerinde değerler alması yapı geçerliği bakımından önemlidir (Hair, Anderson, Tatham ve Black, 1999). Yapilan DFA sonucunda her bir madde için söz konusu regresyon katsayılarının tümü anlamlı bulunmuştur (Tablo 3). 
Türk Futbolunda Video Yardımcı Hakem (VAR) Uygulamasına Yönelik Tutum Ölçeği

Tablo 3. DFA Sonucunda Maddelerin Standart Regresyon Katsayılar

\begin{tabular}{|c|c|c|c|c|}
\hline Maddeler & $\begin{array}{l}\text { Seyir } \\
\text { Zevki }\end{array}$ & $\begin{array}{l}\text { Adaleti } \\
\text { Sağlama }\end{array}$ & $\begin{array}{l}\text { Devam } \\
\text { lilik }\end{array}$ & $\begin{array}{l}\text { Bilgi } \\
\text { Sahipliği }\end{array}$ \\
\hline 15. VAR uygulaması, futbolun seyir zevkini düşürmektedir. & 0,882 & & & \\
\hline 14. VAR uygulaması maçın heyecanını sekteye uğratır. & 0,850 & & & \\
\hline $\begin{array}{l}\text { 12. VAR uygulaması maç esnasında futbolcuların motivasyonunu dü- } \\
\text { şürmektedir. }\end{array}$ & 0,711 & & & \\
\hline 4. VAR sistemi taraftarın seyir zevkini azaltır. & 0,681 & & & \\
\hline $\begin{array}{l}\text { 16. Futbolcular, VAR uygulamasından dolayı gol sevincini tam yaşaya- } \\
\text { mamaktadırlar. }\end{array}$ & 0,599 & & & \\
\hline 26. VAR uygulaması, topun oyunda kalma süresini azaltmaktadır. & 0,596 & & & \\
\hline 3. VAR sistemi, maçı kesintiye uğratmaktadır. & 0,586 & & & \\
\hline $\begin{array}{l}\text { 10. VAR Uygulaması, futbolda güven ortamının oluşmasına katkı sağla- } \\
\text { maktadır. }\end{array}$ & & 0,830 & & \\
\hline 19. VAR sistemi, futbolda adaleti sağlamaktadır. & & 0,827 & & \\
\hline $\begin{array}{l}\text { 28. VAR uygulamasıyla birlikte futbolda daha adaletli kararlar verilmek- } \\
\text { tedir. }\end{array}$ & & 0,768 & & \\
\hline $\begin{array}{l}\text { 8. VAR uygulaması, hakemlerin doğru karar verme oranını arttırmakta- } \\
\text { dır. }\end{array}$ & & 0,748 & & \\
\hline 29. VAR sistemiyle birlikte futbolda tartışmalı pozisyon sayısı azalmıştır. & & 0,697 & & \\
\hline 2. VAR sistemi sayesinde futboldaki pozisyon tartısmaları sona ermiştir. & & 0,614 & & \\
\hline 1. VAR sistemi, futbol için faydalı bir uygulamadır. & & & 0,822 & \\
\hline $\begin{array}{l}\text { 20. VAR sistemi tüm profesyonel liglerde ve kupa maçlarında uygulan- } \\
\text { malıdır. }\end{array}$ & & & 0,762 & \\
\hline 22. VAR sistemi geliştirilerek devam etmelidir. & & & 0,751 & \\
\hline 23. VAR uygulamasına son verilmelidir. & & & 0,664 & \\
\hline 13. Taraftarlar VAR hakkında yeterince bilgi sahibi değildir. & & & & 0,734 \\
\hline 34. Kulüp yöneticileri VAR hakkında yeterince bilgi sahibi değildir. & & & & 0,703 \\
\hline 5. Futbol kamuoyu VAR hakkında yeterince bilgi sahibi değildir. & & & & 0,688 \\
\hline AVE & 0,504 & 0,564 & 0,565 & 0,502 \\
\hline
\end{tabular}

Tablo 3 'te görüldüğü üzere tüm maddelerin standart faktör yükleri (Hair, Anderson, Tatham ve Black, 1999) tarafından alt değer olarak önerilen 0,40'tan büyük ve ölçeğin yapı geçerliği bakımından kabul edilebilir değerlerdir.

Bir ölçeğin yapı geçerliğinin bir diğer önemli göstergesi de faktörlere ait AVE değerleridir. Aynı faktör çatısında toplanan maddelerin gerçekten uyum içerisinde olup olmadığını ortaya koyan AVE değeri $0,5^{\prime}$ ten büyükse faktörün uyum geçerliğinin olduğu sonucuna varılır. Eğer AVE değeri $0,5^{\prime}$ ten küçükse ölçüm hatası kaynaklı varyansın, faktör tarafından açılanan varyanstan büyük olduğu ve dolayısıyla uyum geçerliğinin olmadığı sonucuna varılır (Fornell ve Larcker, 1981). Çok faktörlü bir ölçeğin uyum geçerliğinin olması için her bir faktörün AVE değerinin 0,5'ten büyük olması gerekmektedir (Kartal ve Bardakçı, 2018). Tablo 3’te görüldüğü gibi faktörlere ait AVE 
değerleri "Seyir Zevki" alt boyutu için 0,504 olarak, "Adaleti Sağlama" alt boyutu için 0,564 olarak, "Devamlllık" alt boyutu için 0,565 olarak ve "Bilgi Sahipliğii" alt boyutu için ise 0,502 olarak hesaplanmıştır. Tüm faktörlere ait AVE değerlerinin 0,50 'den büyük değerler aldığı görülmektedir. Bu bulguların da ölçeğin yapı geçerliğine sahip olduğunun önemli bir göstergesi olduğu söylenebilir.

\section{Madde Analizine İlişkin Bulgular}

Bir önceki aşamada ortaya konulan ve yap geçerliğine sahip olduğu tespit edilen 4 alt boyuttan ve 20 maddeden meydana gelen ölçeğin madde analizi işlemleri 250 kişiden elde edilen veriler yardımıyla yapılmıştır. Bu nedenle madde-toplam puan korelasyonuna dayalı madde analizi ve alt-üst gruplara dayalı madde analizi yöntemleri kullanılmıştır.

Madde-Toplam Puan Korelasyonuna Dayalı Madde Analizi:Madde-toplam puan korelasyonu, bir ölçekteki her bir maddeden elde edilen puanlar ile ölçekten alınan toplam puan arasındaki korelasyon ilişkisini ortaya koyan nesnel bir ölçüttür (Tezbaşaran, 1996). Bir maddenin sahip olması gereken madde-toplam korelasyonu katsayısı 0,20'den küçük olmamalıdır. Maddetoplam korelasyonu 0,20'den düşük olan maddeler ölçekten çıkarılmalı, 0,200,30 arasında değer alan maddeler ise zorunlu görülmesi durumunda ölçeğe dâhil edilmelidir. 0,30'dan yüksek değer alan madde-toplam korelasyonuna sahip maddelerin ise ölçeğin geneliyle benzer yönde hareket ettiği sonucuna varılır ve bu maddeler ölçekte kalmalıdır (Büyüköztürk, 2010).

Türk futbolunda VAR uygulamasına yönelik tutum ölçeğinin maddelerine ait madde-toplam korelasyon puanları hesaplanmış ve elde edilen bulgular Tablo 4'te gösterilmiştir. 
Tablo 4. Madde-Toplam Puan Korelasyonlan

\begin{tabular}{llll}
\hline Madde & Madde-Toplam Korelasyonu & Madde & Madde-Toplam Korelasyonu \\
\hline Madde 1 & 0,631 & Madde 15 & 0,675 \\
\hline Madde 2 & 0,441 & Madde 16 & 0,511 \\
\hline Madde 3 & 0,536 & Madde 19 & 0,625 \\
\hline Madde 4 & 0,594 & Madde 20 & 0,576 \\
\hline Madde 5 & 0,339 & Madde 22 & 0,531 \\
\hline Madde 8 & 0,567 & Madde 23 & 0,585 \\
\hline Madde 10 & 0,683 & Madde 26 & 0,550 \\
\hline Madde 12 & 0,593 & Madde 28 & 0,578 \\
\hline Madde 13 & 0,307 & Madde 29 & 0,519 \\
\hline Madde 14 & 0,651 & Madde 34 & 0,364 \\
\hline
\end{tabular}

Bulguları Tablo 4'te verilen madde analizi işlemi sonucunda ölçekte yer alan 20 adet maddenin tamamının madde-toplam korelasyon değerlerinin 0,30'dan büyük olduğu belirlenmiştir. Dolayısıyla maddelerin hepsinin de ölçeğin geneliyle ayn yönde hareket ettiği ve bu nedenle ölçekten madde çıarılmaması gerektiği sonucuna varılmıştır.

Alt Üst Gruplara Dayalı Madde Analizi: Likert tipinde ölçek geliştirme çalışmalarında ayırt ediciliği yüksek olan maddeleri seçebilmek için alt ve üst gruplara dayalı madde analizi işlemi yapılmaktadır (Turgut ve Baykul, 1992). Bu bağlamda Türk futbolunda VAR uygulamasına yönelik tutum ölçeğinde yer alan 20 maddenin ayırt ediciliklerini incelemek amacıyla 250 bireyin ölçekten elde ettikleri puan büyükten küçüğe doğru sıralanmıştır. Sonrasında $\% 27$ 'lik alt ve üst grupta bulunan $68^{\prime}$ er kişinin toplam puan ortalamaları bağımsız örnekler için $t$ testi ile hem ölçeğin tamamı hem de her bir madde için karşılaştırılmıştır (Tablo 5 ve Tablo 6).

Tablo 5. 20 Maddelik Ölçeğin Bütününe Yönelik Alt ve Üst Grup Ortalamalarna İlişkint Testi

\begin{tabular}{llllll}
\hline & $\mathbf{N}$ & \multicolumn{1}{c}{$\overline{\boldsymbol{X}}$} & SD & T & p \\
\cline { 1 - 4 } Alt Grup & 68 & 53,65 & 12,96 & \multirow{2}{*}{39,576} & 0,000 \\
\hline Üst Grup & 68 & 120,76 & 5,25 & & \\
\hline
\end{tabular}

Alt ile üst grup puan ortalamaları arasındaki farkın istatistiksel olarak manidar olduğu söylenebilir $(\mathrm{t}=39,576 ; \mathrm{p}<0,05)$. 
Tablo 6. Maddelerin Ayırt Ediciliğine İlişkin t Testi Sonuçlan

\begin{tabular}{|c|c|c|c|c|c|c|c|c|c|c|c|}
\hline Madde & Grup & $\mathbf{N}$ & $\overline{\mathbf{X}}$ & ss & $\begin{array}{l}t \\
\text { (p) }\end{array}$ & Madde & Grup & $\mathbf{N}$ & $\overline{\mathbf{X}}$ & ss & $\begin{array}{l}t \\
\text { (p) }\end{array}$ \\
\hline \multirow{2}{*}{ Madde 1} & Üst & 68 & 6,95 & 0,20 & \multirow{2}{*}{$\begin{array}{l}14,074 \\
(0.000)\end{array}$} & \multirow{2}{*}{ Madde 15} & Üst & 68 & 6,35 & 1,15 & \multirow{2}{*}{$\begin{array}{l}19,277 \\
(0.000) \\
\end{array}$} \\
\hline & Alt & 68 & 3,54 & 1,98 & & & Alt & 68 & 2,08 & 1,41 & \\
\hline \multirow{2}{*}{ Madde 2} & Üst & 68 & 5,26 & 1,74 & \multirow{2}{*}{$\begin{array}{l}12,406 \\
(0.000) \\
\end{array}$} & \multirow{2}{*}{ Madde 16} & Üst & 68 & 5,77 & 1,65 & \multirow{2}{*}{$\begin{array}{l}13,927 \\
(0.000)\end{array}$} \\
\hline & Alt & 68 & 1,94 & 1,35 & & & Alt & 68 & 1,88 & 1,60 & \\
\hline \multirow{2}{*}{ Madde 3} & Üst & 68 & 5,79 & 1,51 & \multirow{2}{*}{$\begin{array}{l}15,645 \\
(0.000) \\
\end{array}$} & \multirow{2}{*}{ Madde 19} & Üst & 68 & 6,70 & ,71 & \multirow{2}{*}{$\begin{array}{l}16,506 \\
(0.000)\end{array}$} \\
\hline & Alt & 68 & 1,80 & 1,45 & & & Alt & 68 & 2,77 & 1,82 & \\
\hline \multirow{2}{*}{ Madde 4} & Üst & 68 & 6,36 & 1,33 & \multirow{2}{*}{$\begin{array}{l}17,738 \\
(0.000)\end{array}$} & \multirow{2}{*}{ Madde 20} & Üst & 68 & 6,89 & 42 & \multirow{2}{*}{$\begin{array}{l}12,498 \\
(0.000)\end{array}$} \\
\hline & Alt & 68 & 2,04 & 1,50 & & & Alt & 68 & 3,55 & 2,16 & \\
\hline \multirow{2}{*}{ Madde 5} & Üst & 68 & 3,75 & 1,95 & \multirow{2}{*}{$\begin{array}{l}4,370 \\
(0.000)\end{array}$} & \multirow{2}{*}{ Madde 22} & Üst & 68 & 6,95 & ,20 & \multirow{2}{*}{$\begin{array}{l}8,892 \\
(0.000)\end{array}$} \\
\hline & Alt & 68 & 2,45 & 1,46 & & & Alt & 68 & 4,35 & 2,40 & \\
\hline \multirow{2}{*}{ Madde 8} & Üst & 68 & 6,75 & 0,77 & \multirow{2}{*}{$\begin{array}{l}13,258 \\
(0.000)\end{array}$} & \multirow{2}{*}{ Madde 23} & Üst & 68 & 6,94 & 38 & \multirow{2}{*}{$\begin{array}{l}11,037 \\
(0.000)\end{array}$} \\
\hline & Alt & 68 & 3,25 & 2,03 & & & Alt & 68 & 3,67 & 2,40 & \\
\hline \multirow{2}{*}{ Madde 10} & Üst & 68 & 6,73 & 0,58 & \multirow{2}{*}{$\begin{array}{l}19,870 \\
(0.000)\end{array}$} & \multirow{2}{*}{ Madde 26} & Üst & 68 & 6,02 & 1,48 & \multirow{2}{*}{$\begin{array}{l}14,760 \\
(0.000)\end{array}$} \\
\hline & Alt & 68 & 2,41 & 1,69 & & & Alt & 68 & 2,05 & 1,64 & \\
\hline \multirow{2}{*}{ Madde 12} & Üst & 68 & 6,35 & 1,27 & \multirow{2}{*}{$\begin{array}{l}16,306 \\
(0.000)\end{array}$} & \multirow{2}{*}{ Madde 28} & Üst & 68 & 6,76 & ,83 & \multirow{2}{*}{$\begin{array}{l}13,341 \\
(0.000)\end{array}$} \\
\hline & Alt & 68 & 2,42 & 1,51 & & & Alt & 68 & 3,32 & 1,95 & \\
\hline \multirow{2}{*}{ Madde 13} & Üst & 68 & 3,63 & 1,96 & 3,623 & & Üst & 68 & 6,39 & 1,13 & 13,744 \\
\hline & Alt & 68 & 2,48 & 1,71 & $(0.000)$ & & Alt & 68 & 2,94 & 1,73 & $(0.000)$ \\
\hline & Üst & 68 & 6,19 & 1,17 & 21,520 & & Üst & 68 & 4,14 & 2,17 & 3,735 \\
\hline & Alt & 68 & 1,76 & 1,22 & $(0.000)$ & & Alt & 68 & 2,85 & 1,85 & $(0.000)$ \\
\hline
\end{tabular}

Tablo 6'daki bulgulara göre, ölçekte yer alan 20 adet maddenin her birine ait alt ve üst grup ortalama puanları arasında manidar farklılık bulunduğu tespit edilmiştir $(p<0,05)$. Bu bulgulara göre ölçekte yer alan 20 maddenin tamamının ayırt ediciliğe sahip olduğu ve dolayısıyla ölçekte kalması gerektiği söylenebilir.

\section{Ölçeğin Güvenirliğine İlişkin Bulgular}

Ölçeğe Ait Test-Tekrar-Test Güvenirliği: Bu aşamada geliştirilen Türk futbolunda VAR uygulamasına yönelik tutum ölçeğinin kararlılı̆̆1 42 kişiden elde edilen veriler yardımıyla test-tekrar-test yöntemiyle ele alınmıştır. Kararlılık, tutumlar gibi devamlılı̆̆ olan ve kolaylıkla değişime uğramayan özellikleri ölçmeyi hedefleyen ölçme araçlarında aranan bir güvenirlik kriteridir (Tavşancll, 2002). Test-tekrar-test uygulamasında ölçeğin on beş gün-bir ay arayla iki kez uygulanmasından sonra, iki ölçümden alınan puan ortalamaları arasında istatistiksel olarak manidar farkın bulunmaması, iki ölçüm sonucunun benzer olduğunu göstermektedir (Aksayan ve Gözüm, 2002). 
Üç hafta ara ile uygulanan Türk futbolunda VAR uygulamasına yönelik tutum ölçeğinin ve alt boyutlarının iki uygulama puanları arasında farklılık olup olmadığının tespiti, bağımlı gruplar t testi ile sınanmıştır. Ayrıca iki uygulama arasındaki Pearson korelasyon katsayıları hesaplanarak ölçeğin ve alt boyutlarına ait kararlılık katsayıları elde edilmiştir (Tablo 7).

Tablo 7. Test-Tekrar-Test Uygulaması Sonuçları

\begin{tabular}{|c|c|c|c|c|c|c|c|}
\hline & Uygulamalar & $\mathbf{N}$ & Ort. & ss & $t$ & $\mathrm{p}$ & $r(p)$ \\
\hline \multirow{2}{*}{ Seyir Zevki } & Birinci Uygulama & 42 & 29,24 & 12,15 & \multirow{2}{*}{1,000} & \multirow{2}{*}{0,323} & 0,998 \\
\hline & İkinci Uygulama & 42 & 29,17 & 12,06 & & & $(0,000)$ \\
\hline \multirow{2}{*}{ Adaleti Sağlama } & Birinci Uygulama & 42 & 30,69 & 8,24 & \multirow{2}{*}{0,726} & \multirow{2}{*}{0,472} & 0,995 \\
\hline & İkinci Uygulama & 42 & 30,59 & 8,37 & & & $(0,000)$ \\
\hline \multirow{2}{*}{ Devamlılık } & Birinci Uygulama & 42 & 19,11 & 3,96 & \multirow{2}{*}{0,123} & \multirow{2}{*}{0,903} & 0,951 \\
\hline & İkinci Uygulama & 42 & 19,09 & 4,04 & & & $(0,000)$ \\
\hline \multirow{2}{*}{ Bilgi Sahipliği } & Birinci Uygulama & 42 & 15,29 & 4,96 & \multirow{2}{*}{1,480} & \multirow{2}{*}{0,146} & 0,989 \\
\hline & İkinci Uygulama & 42 & 15,12 & 4,80 & & & $(0,000)$ \\
\hline \multirow{2}{*}{ Toplam } & Birinci Uygulama & 42 & 94,16 & 15,96 & \multirow{2}{*}{0,714} & \multirow{2}{*}{0,479} & 0,994 \\
\hline & İkinci Uygulama & 42 & 93,97 & 16,28 & & & $(0,000)$ \\
\hline
\end{tabular}

Tablo 7'deki t testi sonuçlarına göre, hem ölçeğin tamamına hem alt boyutlarına ait birinci ve ikinci ölçüm sonuçları arasında manidar bir farklılık bulunmadığı görülmektedir ( $p>0,05)$. Bu şekilde iki uygulamada da benzer sonuçların ortaya çıkması, ölçeğin güvenirliğinin bir göstergesidir. Diğer yandan, test tekrar test kararlılık katsayıları da ölçeğin tamamı ve alt boyutları için 1'e yakın, oldukça yüksek ve anlamlı değerlerdir.

İç Tutarlılık Analizi: Likert tipi ölçek geliştirilirken temel kabullerden birisi, ölçülmesi amaçlanan özellik ile ölçekteki maddeler arasında ilişki bulunmasıdır. Başka bir ifadeyle, her maddenin temelde aynı tutumu ölçmesi gerekliliği varsayımı bulunmaktadır (Tavşancıl, 2002). Bu varsayımın kontrolü ve güvenirlik düzeyinin belirlenmesi için literatürde Cronbach $\alpha$ katsayısının kullanılması uygun görülmektedir. Ölçeğin $\alpha$ katsayısı ne kadar yüksekse ölçekteki maddelerin de o derece birbiriyle tutarlı olduğu yorumu yapılabilir (Tezbaşaran, 1996). Cronbach $\alpha$ iç tutarlılık katsayısı diğer güvenirlik katsayıları gibi, 0.70 'ten büyük bir değer alırsa ölçeğin güvenilir olduğu yönünde yorumlanabilir (Kartal ve Bardakçı, 2018).

Geliştirilmekte olan Türk futbolunda VAR uygulamasına yönelik tutum ölçeğinin iç tutarlılığa bağlı güvenirliği öncelikle, madde analizi aşamasında 
ulaşılan 250 kişiden elde edilen veriler yardımıyla ölçeğin geneline ve alt boyutlarına ait Cronbach $\alpha$ katsayıları hesaplanarak incelenmiştir (Tablo 8).

Tablo 8. Ölçek ve Alt boyutlarna Ait Cronbach a Katsayılan

\begin{tabular}{lcc}
\hline & Madde Sayısı & Cronbach $\alpha$ Değeri \\
\hline Seyir Zevki & 7 & 0,875 \\
\hline Adaleti Sağlama & 6 & 0,884 \\
\hline Devamlılık & 4 & 0,851 \\
\hline Bilgi Sahipliği & 3 & 0,741 \\
\hline Toplam & 20 & 0,893 \\
\hline
\end{tabular}

Tablo 8'deki sonuçlara göre, elde edilen değerler 0,70 'ten büyük ve ölçeğin güvenirliği için yeterli değerlerdir.

Bir ölçme aracının iç tutarlılı̆̆ını belirlemeye yönelik bir diğer yaklaşım ise yarılama yöntemidir. Bu yöntemde ölçek birbirine eş iki yarıya bölünerek, yarı ölçekler arasındaki eşdeğerlilik incelenmektedir. Eğer yarı ölçeklerin ölçüm sonuçları arasında anlamlı ve yüksek bir korelasyon ilişkisi mevcutsa ölçeğin iç tutarlılığının yüksek olduğu sonucuna varılmaktadır. Bu korelasyon katsayısına bağlı olarak hesaplanan Spearman-Brown katsayısı, bir iç tutarlılık katsayısıdır ve bu bakımdan güvenirliğin göstergesi olarak kabul edilmektedir (Kartal ve Bardakçı, 2018). Bu aşamada geliştirilmekte olan Türk futbolunda VAR uygulamasına yönelik tutum ölçeği, madde sıra numaralarına göre 10'ar maddeden oluşan iki yarı ölçeğe bölünmüştür. Yapılan korelasyon analizi sonucunda yarı ölçekler arasındaki korelasyon katsayısı 0,837 olarak, Spearman-Brown yarılama güvenirlik katsayısı ise 0,911 olarak bulunmuştur. Bu sonuca göre, ölçeğin iç tutarlılığı ve güvenirliğinin yüksek olduğu belirlenmiştir.

\section{Sonuç ve Öneriler}

Mevcut çalışmada, araştırmacılara kişilerin Türk futbolunda VAR uygulamasına yönelik tutumlarını ölçmesine imkân sağlayacak Likert tipinde bir ölçeğin geliştirilmesi ve söz konusu ölçeğin güvenirlik ve geçerlik analizlerinin yapılması amaçlanmıştır. Bu amaçla araştırmacılar tarafından 43 maddeden oluşan bir madde havuzu oluşturulmuş, uzman önerileri doğrultusunda 5 madde kapsam dişında bırakılarak 38 maddelik bir taslak ölçek meydana getirilmiştir. Taslak ölçeğe dil ve anlatım yönünden uzmanlardan alınan görüşler dikkate alınarak uygulamadan önceki son hali verilmiştir. 
Ölçeğin faktör yapısının belirlenmesi amacıyla yapılan AFA sonucunda hiç bir faktöre yerleşmeyen ve iki veya daha fazla faktörde binişik olan maddeler belirlenerek ölçekten çıkarılmış, sonuç olarak 4 alt boyuttan ve 20 maddeden oluşan bir ölçme yapısı elde edilmiştir. Bu yapı toplam varyansın $\% 64,225$ 'ini açıklamaktadır. Literatürde toplam açıklanan varyans için alt s1nırın \%40 ile \%60 arasında olması gerektiği üzerine görüşler bulunmaktadır (Karagöz, 2016). Buna göre ortaya konulan yapının açıkladığı varyansın yapı geçerliği bakımından yeterli olduğu söylenebilir. Büyüköztürk (2002)'e göre AFA sonucunda elde edilen maddelere ait faktör yükü değerlerinin ise 0,45 üzerinde değerler alması yeterli görülmektedir. Geliştirilen ölçeğin maddelerine ait faktör yükü değerlerinin 0,617-0,823 aralığında değiştiği belirlenmiştir. Bu bağlamda maddelerin faktör yükü değerlerinin de oldukça yüksek ve yeterli değerler olduğu ifade edilebilir.

AFA sonrası bağımsız bir diğer örneklem üzerinde yapılan DFA sonucunda 4 alt boyuttan ve 20 maddeden oluşan modelin verilerle iyi derecede uyum gösterdiği saptanmış, bu suretle AFA ile ortaya konulan ölçek yapısının başka bir örneklem üzerinde de geçerli olduğu tespit edilmiştir. DFA sonucunda tüm maddelerin faktör yükleri oldukça yüksek ve anlamlı bulunmuş, faktörlere ait AVE değerlerinin tamamı alt sınır olan 0,50'den yüksek olarak hesaplanmıştır. Tüm bu bulgular Kartal ve Bardakçı (2018)'e göre ölçeğin yapı geçerliğine sahip olduğunun birer göstergesidir.

Türk futbolunda VAR uygulamasına yönelik tutum ölçeğinin maddelerine ilişkin öncelikle madde-toplam korelasyonuna dayalı madde analizi uygulaması yapılmış, analiz sonucunda tüm maddelerin madde-toplam korelasyon katsayılarının literatürde genel kabul gören alt sınır olan 0,30'dan yüksek değerler olduğu tespit edilmiştir (Büyüköztürk, 2010). Ayrıca yapılan altüst gruplara dayalı madde analizi sonucunda ölçeğin tamamının ve tüm maddelerinin ayırt edicilik özelliğine sahip oldukları görülmüştür. Her iki madde analizi sonucunda da ölçekten çıkarılmasına gerek olan maddenin bulunmadığı sonucuna varılmıştır.

Türk futbolunda VAR uygulamasına yönelik tutum ölçeğinin güvenirlik analizleri kararlılığı ve iç tutarlılığı bağlamında ele alınmıştır. Ölçeğin kararlılığını belirlemeye yönelik yapılan test-tekrar-test uygulaması sonucunda, ölçeğin ve alt boyutlarının üç hafta arayla aynı örnekleme uygulanması sonucu elde edilen puanların benzer olduğu, kararlılık katsayılarının güvenir- 
lik katsayıları için kritik değer olan 0,70'ten büyük değerler aldığı görülmüştür. Bu sonuçların geliştirilmekte olan ölçeğin ölçüm sonuçlarının değişmezliğini ve kararlılığını ifade ettiği ve ölçeğin güvenilir olduğunu gösterdiği söylenebilir.

Son olarak Türk futbolunda VAR uygulamasına yönelik tutum ölçeğinin iç tutarlılığa sahip olup olmadığı ölçeğin tümüne ve alt boyutlarına ait Cronbach $\alpha$ katsayıları hesaplanarak ve yarılama yöntemi kullanılarak ayrı ayrı incelenmiştir. Ölçeğin tamamı ve alt boyutları için hesaplanan Cronbach $\alpha$ katsayısı değerlerinin yeterli derecede büyük olduğu, buna dayanarak ölçeğin iç tutarlılığa sahip olduğu tespit edilmiştir. Yarılama yöntemi sonucunda elde edilen Spearman-Brown güvenirlik katsayısı da 0,911 olarak hesaplanmış olup bu değer de ölçeğin yüksek iç tutarlılığa ve güvenirliğe sahip olduğunu desteklemektedir.

Spor bilimleri literatürü incelendiğinde hakem, sporcu, antrenör, yönetici ve taraftar unsurlarının yer aldığı ulusal düzeyde farklı psikososyal envanter araştırmları ve tutum çalışmaları mevcuttur. Kelecek ve ark. (2016), sporcuların tükenmişlik düzeyi ölçeğinin Türkçe uyarlaması çalışmasında iç tutarlık katsayılarının 0,75 ile 0,87 arasında değiştiğini belirlemiştir. Karaçam ve Pulur (2018) Hakemler İçin Mesleki Haz Ölçeği uyarlama araştırmasında cronbach alpha iç tutarlık katsayısını 0,83 olarak bulmuştur. Hakemlerin psikososyal durumlarını belirleme amaçlı uyarlanan bir başka araştırmada ise iç tutarlık katsayısını 0,90 olarak bulmuştur (Karaçam ve Pulur, 2017). Literatürdeki araştırmaların hedef noktası spor unsurlarının (sporcu, hakem, antrenör vb.) psikososyal durumların belirlemeye yönelik oldukları görülmektedir. Ancak mevcut araştırmamız yenilikçi olarak görülen VAR sisteminin; seyir zevki, kural uygulaması ve müsabaka sonuç etkileri gibi kriterler ile sporcu, antrenör, taraftar, yönetici gibi spor katılımcılarının bakış açısından değerlendirme olanağı sağlayacaktır.

Sonuç olarak, geliştirilmiş olan ve EK 1'de verilen Türk futbolunda VAR uygulamasına yönelik tutum ölçeğinin geçerli ve güvenilir bir ölçme aracı olduğu söylenebilir.

Bununla birlikte araştırmanın bazı sınırlılıkları mevcuttur. Bu sınırlılıklarla birlikte araştırmacılara önerilen bazı hususlar şu şekilde sıralanabilir:

- Araştırmada ölçeğin madde havuzu 43 maddeden oluşmuştur. Yapılacak çalışmalarda VAR uygulamasına yönelik farklı görüşleri yansıtacak 
Türk Futbolunda Video Yardımcı Hakem (VAR) Uygulamasına Yönelik Tutum Ölçeği Geliştirilmesi

yeni maddeler eklenerek madde havuzu genişletilebilir ve daha kapsamlı ölçme araçları geliştirilebilir.

- Araştırmanın bulguları çalışma grubundan elde edilen verilerle sınırlıdır. Yapılacak çalışmalarda daha geniş çalışma gruplarına ulaşılarak daha kapsamlı bulgulara ulaşılabilir ve ölçeğin güvenirliği ve geçerliği sınanabilir. 


\title{
EXTENDED ABSTRACT
}

\section{Development of The Attitude Scale Towards Video Assistant Referee (Var) in Turkish Football}

\author{
Recep Fatih Kayhan - Sait Bardakçı - Çağdaş Caz \\ Recep Tayyip Erdoğan University, Cumhuriyet University, Yozgat Bozok University
}

Continuing to increase both the audience / fans and the pleasure of watching from the past to the present day, football has become one of the most watched and followed sports branches today. The decisions made by the referees during the football match directly affect the outcome of the match. The decisions made by the referees often cause controversy. Avoiding erroneous decisions is possible with developing technology. The Video Assistant Referee (VAR) developed for this purpose provides great convenience to the judges at the final decision point. The Video Assistant Referee System, which is used not only for the goal position but also for the critical positions in the match, helps the referees to decide in critical moments during the match. The referee made his final decision after evaluating the backward positions by stopping the match by creating assistive tools with computer vision techniques from the data obtained by the cameras. In this context, VAR, which is also referred to as auxiliary technological innovations, is called the computerized system that enables the referees to make the right decision by processing the images taken with high resolution and quality cameras in real time (Peker ve Özkaraca, 2018). However, the debate in football public opinion about the implementation of the VAR remains fresh. Various stakeholders of football share their positive or negative opinions about the application with the football public. The purpose of working with these thoughts is to develop a scale for measuring individuals' attitudes towards VAR practice in Turkish football. For this purpose, a pool of 43 items was created by the researchers, and 5 items were excluded from the scope of expert opinions, and a 38-item draft scale was obtained. Research the following football competitions in Turkey, he joined 1011 people who have enough knowledge about football. The sampling method was used to identify the study group. Data was collected from the participants through a face-to-face survey. People were asked whether they had fol- 
lowed football matches and whether they had enough information about football game rules, and a scale form was applied to those who stated that they had sufficient information. The data of 415 for exploratory factor analysis and 304 for confirmatory factor analysis were used in the analysis of structure validity and these two samples are independent from each other. In the reliability analysis of the scale, data belonging to 250 people were evaluated in the test-retest application, while the item analysis and the calculation of the Cronbach Alpha coefficient were evaluated. The developed scale is a 7-point Likert type scale. The items in the scale are "7 = I totally agree", "6 = I agree", "5 = I partially agree", " 4 = I am indecisive", " 3 = I strongly disagree", " 2 = I disagree" and " 1 = Definitely I disagree". The scores obtained from the scale show that the level of participation in the proposition in that item is high as it approaches seven and it is low when it approaches one. The items with the statement reflecting the negative attitude about the subject are scored as the opposite of the above coding in the scoring phase. The positive and negative opinions expressed about the VAR implementation in the Turkish football public have been taken into consideration. In addition, 24 positive and 19 negative statements were organized by taking the opinions of the experts who have worked as a football referee, football coach, and who have studies in the field of football research and those who have studies in the field of attitude. In this way, the item pool of the scale consists of 43 items in total. Experts evaluated whether each item in the item pool should be included in the scale and as a result of this process, 5 items out of the scale were removed from the scale in line with the recommendations of the experts. Three of the items removed are statements expressing positive and two expressing negative attitudes. In this way, a draft scale consisting of 38 items, 21 of which were positive and 17 negative, was obtained. The statements in the scale were rearranged and the draft scale was finalized by applying to the knowledge of 2 academicians who are experts in the field of Turkish Language about whether the expressions of the items in the draft scale are appropriate in terms of expression and the suitability of the spelling rules. Exploratory and confirmatory factor analyzes, test-retest method and internal consistency analysis were used as statistical methods. In order to determine the factor structure of the attitude scale towards VAR application in Turkish football, AFA was applied to 38 items in the draft scale using the Principal Components Analysis and Varimaks Rotation methods. The factor load values of the items obtained as a result of AFA 
are considered to be higher than 0.45 . It was determined that the factor load values of the items of the developed scale ranged in the range of $0.617-0.823$. In this context, it can be stated that the factor load values of the items are quite high and sufficient values. As a result of the CFA performed on another independent sample after AFA, it was determined that the model consisting of 4 sub-dimensions and 20 items was in good agreement with the data, thus, the scale structure revealed with AFA was also valid on another sample. As a result of CFA, the factor loads of all items were found to be quite high and significant, and all AVE values of the factors were calculated to be higher than the lower limit of 0.50 . As a result of the test-retest application to determine the stability of the scale, it was observed that the stability coefficients received values greater than 0.70 , which is the critical value for the reliability coefficients. It can be said that these results indicate that the scale under development expresses the stability and stability of the measurement results and shows that the scale is reliable. Finally, whether the attitude scale towards VAR application in Turkish football has internal consistency or not, the Cronbach $\alpha$ coefficients of the whole scale and its sub-dimensions were calculated separately by using the half-way method. The Spearman-Brown reliability coefficient obtained as a result of the splitting method was calculated as 0.911 , which supports the scale's high internal consistency and reliability. It was concluded that the scale developed according to these findings is a reliable and valid measurement tool.

\section{Kaynakça / References}

Aksayan, S. ve Gözüm, S. (2002). Guide for intercultural scale adaptation: Psychometric features and intercultural comparison. Journal of Research and Development in Nursing, 4(2),9-20.

Arkonaç, S. A. (2001). Sosyal psikoloji. 2. Bsm. İstanbul: Alfa Basım Yayım Dağıtım. Büyüköztürk, Ş. (2002). Sosyal bilimler için veri analizi el kitabı. 2. Bsk. Ankara: Pegem Yayınclik.

Büyüköztürk, Ş. (2010). Sosyal bilimler için veri analizi el kitabı. 12. Baskı. Ankara: Pegem Akademi.

Dandıl, E. ve Özkul, İ. (2019). Futbol maçları için bilgisayarlı görü destekli gol karar sistemi (golkasis): Bir prototip çalışma. Gu J Sci. Part C, 7(1),213-24.

Dizdar, C. (2019). VAR, futbolun cenaze merasimidir!. TRT Akademi, 4(8),522-35. 
Engin, S.G. ve Çelik, V.O. (2019). VAR'lĭ̆ın yeter! Hakemlerin gözünden video yardımc hakem sistemi. International Journal of Sport Culture and Science, 7(2),53-68.

Ford, G.G., Gallagher, S.H., Lacy, B.A., Bridwell, A.M. ve Goodwin, F. (1999). Repositioning the home plate umpire to provide enhanced perceptual cues and more accurate ball-strike judgments. Journal of Sports Behavior, 22(1),2844.

Fornell. C. ve Larcker, D.F. (1981). Evaluating structural equations models with unobservable variables and measurement error. Journal of Marketing Research, 18(1),39-50.

Gore, G., Rix, G., Wathelet, O. ve Cazemajou, A. (2012). Eliciting and tacit: interviewing to understand bodily practices in jonathan skinner. The Interview: An Ethnographic Approach. $2^{\text {nd }}$ ed. Bloomsbury Academic, 127-42.

Hair, J.F., Anderson, R.E., Tatham, R.L. ve Black, W.C. (1999). Análisis multivariante. Madrid: Prentice Hall.

İnceoğlu, M. (2010). Tutum algı iletişim. Beykent Üniversitesi İletişim ve Tasarım Bölümü. Beykent Üniversitesi Yayınları, İstanbul.

Karaçam, A., ve Pulur, A. (2017). Hakem öz yeterlik ölçeği'nin (HÖYÖ) Türkçeye uyarlama çalişmasi. Journal Of Physical Education \& Sports Science/Beden Egitimi Ve Spor Bilimleri Dergisi, 11(1).

Karaçam, A., ve Pulur, A. (2018). Hakemler için mesleki haz ölçeği: Geçerlik ve güvenirlik çalışması:Himhö. Gaziantep Üniversitesi Spor Bilimleri Dergisi, $3(2), 35-45$.

Karagöz, Y. (2016). Spss ve amos 23 uygulamaln istatistiksel analizler. Ankara: Nobel Akademik Yayıncilik.

Kartal, M. ve Bardakçı, S. (2018). Spss ve amos uygulamalı örneklerle güvenirlik ve geçerlik analizleri. 1. Baskı. Ankara: Akademisyen Yayınevi.

Kartal, M. ve Bardakçı, S. (2019). Tutum ölçekleri. 1. Baskı. Ankara: Akademisyen Yayınevi.

Kelecek, S., Kara, F. M., Çetinkalp, F. Z. K., ve Aş̧̧i, F. H. (2016). Sporcu tükenmişlik ölçeğinin Türkçe uyarlaması. Spor Bilimleri Dergisi, 27(4), 150-161.

Meydan, C.H. ve Şeşen, H. (2015). Yapısal eşitlik modellemesi amos uygulamaları. 2. Baskı. Ankara: Detay Yayıncllı.

Nakip, M. (2006). Pazarlama araştırmaları teknikler ve spss destekli uygulamalar. Ankara: Seçkin Yayıncilık.

Orta, L. (2018). Futbol oyun kurallarında video yardıma hakem Sistemi (Var). 16th International Sport Sciences Congress, 31th October-03rd November, 2018. 
Paolo-Spagnolo, M.L., Pier, L.M., Massimiliano, N., Ettore, S. ve Arcangelo, D. (2013). Non- invasive soccer goal line technology: a real case study. Ieee Computer Society. 2013 Ieee Conference on Computer Vision And Pattern Recognition Workshops. 2328 June 2013. Portland, Or, USA.

Peker, M ve Özkaraca, O. (2018). Büyük ölçekli veri setleri için gpu huzlandırmalı melez bir ga-svm: cu-ga-svm. Gazi Üniversitesi Fen Bilimleri Dergisi Part C: Tasarmm ve Teknoloji, 6(3),581-91.

Tavşancıl, E. (2002). Tutumların ölçülmesi ve spss ile veri analizi. 1. Bask1. Ankara: Nobel Basım Yayın.

Tezbaşaran, A.A. (1996). Likert tipi ölçek geliştirme kılavuzu. Ankara: Psikologlar Derneği Yayınları.

TFF, Başkanı Nihat Özdemir, MHK Kış Semineri'nde konuştu (Ocak 7, 2020). TFF. 11/01/2020 tarihinde https://tff.org/default.aspx?pageID=248\&ftxtID=32772 adresinden erişilmiştir.

Turgut, M.F. ve Baykul, Y. (1992). Ölçekleme teknikleri. Ankara: Ösym Yayınları.

Ugondo, P.L. ve Tsokwa, M. (2019). Interpreting video assistant referee and goalline technology communication: the pitch-based referees perspectives. International Journal of Trend in Scientific Research and Development, 3(4),105862. 


\section{Ekler}

\section{EK 1. TÜRK FUTBOLUNDA VIDEO YARDIMCI HAKEM (VAR) ÖLÇEĞİ}

\begin{tabular}{|c|c|c|c|c|c|c|c|}
\hline ÖLÇEK, ALT BOYUT VE MADDELERİ & 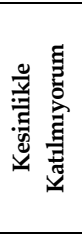 & 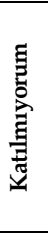 & 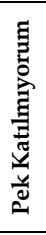 & 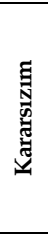 & 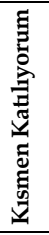 & 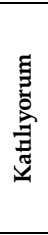 & ت \\
\hline \multicolumn{8}{|l|}{ Seyir Zevki } \\
\hline *VAR uygulaması, futbolun seyir zevkini düşürmektedir. & 1 & 2 & 3 & 4 & 5 & 6 & 7 \\
\hline *VAR uygulaması maçın heyecanını sekteye uğratır. & 1 & 2 & 3 & 4 & 5 & 6 & 7 \\
\hline *VAR sistemi taraftarın seyir zevkini azaltır. & 1 & 2 & 3 & 4 & 5 & 6 & 7 \\
\hline $\begin{array}{l}\text { *Futbolcular, VAR uygulamasından dolayı gol sevincini } \\
\text { tam yaşayamamaktadırlar. }\end{array}$ & 1 & 2 & 3 & 4 & 5 & 6 & 7 \\
\hline *VAR sistemi, maçı kesintiye uğratmaktadır. & 1 & 2 & 3 & 4 & 5 & 6 & 7 \\
\hline $\begin{array}{l}\text { *VAR uygulaması maç esnasında futbolcuların motivasy- } \\
\text { onunu düşürmektedir. }\end{array}$ & 1 & 2 & 3 & 4 & 5 & 6 & 7 \\
\hline $\begin{array}{l}\text { *VAR uygulaması, topun oyunda kalma süresini azalt- } \\
\text { maktadır. }\end{array}$ & 1 & 2 & 3 & 4 & 5 & 6 & 7 \\
\hline \multicolumn{8}{|l|}{ Adaleti Sağlama } \\
\hline $\begin{array}{l}\text { VAR sistemiyle birlikte futbolda tartışmalı pozisyon sayısı } \\
\text { azalmıştır. }\end{array}$ & 1 & 2 & 3 & 4 & 5 & 6 & 7 \\
\hline $\begin{array}{l}\text { VAR uygulamasiyla birlikte futbolda daha adaletli } \\
\text { kararlar verilmektedir. }\end{array}$ & 1 & 2 & 3 & 4 & 5 & 6 & 7 \\
\hline $\begin{array}{l}\text { VAR sistemi sayesinde futboldaki pozisyon tartışmaları } \\
\text { sona ermiştir. }\end{array}$ & 1 & 2 & 3 & 4 & 5 & 6 & 7 \\
\hline VAR sistemi, futbolda adaleti sağlamaktadır. & 1 & 2 & 3 & 4 & 5 & 6 & 7 \\
\hline $\begin{array}{l}\text { VAR uygulaması, futbolda güven ortamının oluşmasına } \\
\text { katkı sağlamaktadır. }\end{array}$ & 1 & 2 & 3 & 4 & 5 & 6 & 7 \\
\hline $\begin{array}{l}\text { VAR uygulaması, hakemlerin doğru karar verme oranını } \\
\text { arttırmaktadır. }\end{array}$ & 1 & 2 & 3 & 4 & 5 & 6 & 7 \\
\hline \multicolumn{8}{|l|}{ Devamlilik } \\
\hline VAR sistemi geliştirilerek devam etmelidir. & 1 & 2 & 3 & 4 & 5 & 6 & 7 \\
\hline *VAR uygulamasina son verilmelidir. & 1 & 2 & 3 & 4 & 5 & 6 & 7 \\
\hline $\begin{array}{l}\text { VAR sistemi tüm profesyonel liglerde ve kupa maçlarında } \\
\text { uygulanmalıdır. }\end{array}$ & 1 & 2 & 3 & 4 & 5 & 6 & 7 \\
\hline VAR sistemi, futbol için faydalı bir uygulamadır. & 1 & 2 & 3 & 4 & 5 & 6 & 7 \\
\hline \multicolumn{8}{|l|}{ Bilgi Sahipliği } \\
\hline $\begin{array}{l}\text { *Kulüp yöneticileri VAR hakkında yeterince bilgi sahibi } \\
\text { değildir. }\end{array}$ & 1 & 2 & 3 & 4 & 5 & 6 & 7 \\
\hline *Taraftarlar VAR hakkında yeterince bilgi sahibi değildir. & 1 & 2 & 3 & 4 & 5 & 6 & 7 \\
\hline $\begin{array}{l}\text { *Futbol kamuoyu VAR hakkında yeterince bilgi sahibi } \\
\text { değildir. }\end{array}$ & 1 & 2 & 3 & 4 & 5 & 6 & 7 \\
\hline
\end{tabular}

$\left.{ }^{*}\right)$ işaretli maddeler olumsuz anlam içerdiği için puanlama yapılırken tersine kodlama yapılmalıdır. 


\section{Kaynakça Bilgisi / Citation Information}

Kayhan, R. F., Bardakçı, S. ve Caz, Ç. (2020). Türk futbolunda video yardımc hakem (VAR) uygulamasına yönelik tutum ölçeği geliştirilmesi. OPUS-Uluslararası Toplum Araştırmaları Dergisi, 16(27), 571596. DOI: 10.26466-/opus.673635 